\title{
Nutritional knowledge and habits of adolescents aged 9 to 13 years in Sharjah, United Arab Emirates: a cross- sectional study
}

Nabeel Al-Yateem ${ }^{1,2}$ and Rachel Rossiter ${ }^{2}$

$$
\begin{aligned}
& \text { المعلومـات والعـادات التغذويـة للمر اهقـين الذيـن تـتراوح أعمارهــم بـين } 9 \text { و } 13 \text { سـنة في الثـارقة، الإمـارات العربيـة المتحدة: دراسـة } \\
& \text { مقطعية } \\
& \text { نبيل اليتيم، ريتشيل روسيتر }
\end{aligned}
$$

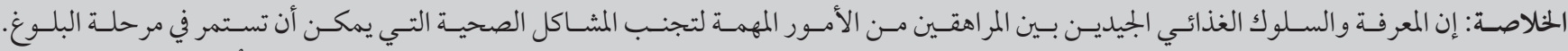

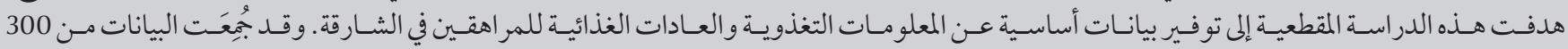

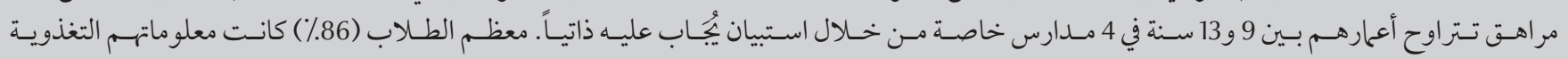

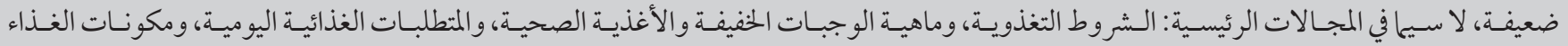

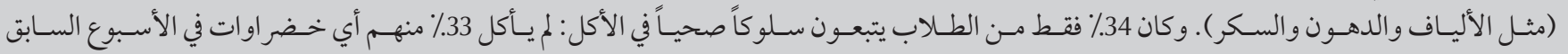

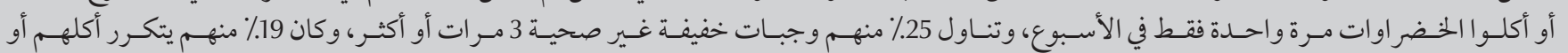

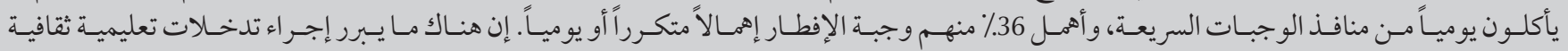

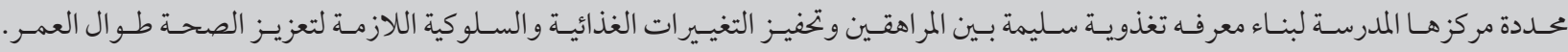

ABSTRACT Good nutritional knowledge and behaviour among adolescents is important to avoid health problems that can continue into adulthood. This cross-sectional study aimed to provide baseline data on nutritional knowledge and eating habits of adolescents in Sharjah. Data were collected from 300 adolescents aged 9-13 years attending 4 private schools using a validated self-administered questionnaire. Most students (86\%) had poor nutritional knowledge, especially in key areas: nutritional terms, what constitutes healthy snacks and foods, daily nutritional requirements and components of food (e.g. fibre, fat, sugar). Only $34 \%$ of the students had healthy eating behaviour: $33 \%$ had eaten none or 1 vegetable only in the previous week, $25 \%$ had eaten unhealthy snacks 3 or more times, $19 \%$ had eaten frequently or daily at fast food outlets, and $36 \%$ had skipped breakfast frequently or daily. Culturally-specific, school-based educational interventions are warranted to build sound nutritional knowledge among adolescents and motivate the diet and behaviour changes needed to promote health throughout the lifespan.

\section{Connaissances nutritionnelles et habitudes alimentaires chez les adolescents aux Émirats arabes unis : étude transversale}

RÉSUMÉ De bonnes connaissances nutritionnelles ainsi que des comportements alimentaires sains sont importants pour les adolescents afin d'éviter les problèmes de santé persistants à l'âge adulte. La présente étude transversale avait pour objectif de fournir des données de base sur les connaissances nutritionnelles et les habitudes alimentaires chez les adolescents à Sharjah. Des données ont été collectées auprès de 300 adolescents âgés de 9 à 13 ans inscrits dans des écoles privées en utilisant un questionnaire auto-administré validé. La plupart des étudiants (86 \%) avaient de faibles connaissances nutritionnelles, notamment dans des domaines essentiels comme la terminologie nutritionnelle, ce qui constitue des en-cas et des aliments sains, les besoins nutritionnels quotidiens et la composition des aliments ( par exemple : fibres, graisses, sucre). Seuls $34 \%$ des étudiants avaient un comportement alimentaire sain ; 33 \% des étudiants n'avaient pas consommé de légumes ou n'en avaient consommé qu'un seul au cours de la semaine précédant l'étude. En outre, $25 \%$ avaient consommé des en-cas mauvais pour la santé trois fois ou plus et $19 \%$ avaient mangé fréquemment ou quotidiennement dans des établissements de restauration rapide. Enfin, 36 \% n'avaient pas pris de petit-déjeuner de façon fréquente ou quotidienne. Des interventions éducationnelles en milieu scolaire, adaptées culturellement, sont requises pour l'acquisition de bonnes connaissances nutritionnelles parmi les adolescents ainsi que pour la motivation de changements de comportements et d'habitudes alimentaires nécessaires afin de promouvoir la santé tout au long de la vie. 


\section{Introduction}

Health problems arising from an excessive intake of calorie-dense foods which lead to obesity and/or nutritional deficiencies as a result of limited intake or poor choice of foods are common in adolescence (1-11). In the adolescent population, rates of obesity have more than quadrupled over the past 30 years (6-8).

The long-term health effects of obesity and nutritional deficiencies in this population are serious. Obesity in adolescence predisposes a young person to heart disease, type 2 diabetes, stroke, several types of cancer and osteoarthritis (2,12-16). It has also been suggested that obesity in adolescence may adversely affect academic performance (12-14,16-21). It is important to remember that obesity and nutritional deficiencies are not mutually exclusive, there may be a double burden for many of both obesity and nutrient deficiencies (such as iron deficiency and zinc deficiency) $(11,22)$.

Growing evidence suggests obesity can be prevented by improving adolescents' knowledge of healthy nutrition, promoting healthy lifestyles and increasing physical activity, in conjunction with changing adolescents' attitudes towards adopting healthy behaviours $(6,21,23$ 26). Schools can and should play a central role in delivering interventions about these issues (27).

During adolescence, young people start to make lifestyle choices and adopt habits which generally become entrenched behaviours as they move into adulthood $(28,29)$. Therefore, adolescence appears to be an ideal time to influence choices and shifts in behaviour and attitudes. Eating behaviours and food choices are usually acquired in childhood but these are further shaped during adolescence and are influenced by a range of factors such as the media, socioeconomic status, peers, family and personal nutritional knowledge $(19,28,30)$.

In the United Arab Emirates (UAE) and the wider Gulf Cooperation Council (GCC) countries, rapid urbanization and transition to a Westernized lifestyle has markedly changed nutritional intake and eating behaviours (e.g. increased consumption of fast foods, unhealthy snacks), especially among the adolescent population (30,31). According to the World Health Organization, 74\% of the Emirati population is overweight and $37 \%$ is obese $(7,8)$. According to a large-scale study in the UAE, almost $28 \%$ of male adolescents and $40 \%$ of female adolescents were overweight or obese. Furthermore, physical activity levels were low, especially among female Emiratis and those living in urban areas (30).

Given that adolescence is the stage at which lifestyle behaviours and habits are adopted that will be carried into adulthood and the changing nutrition and lifestyle in the UAE, health care and educational providers need to pay careful attention this issue. Targeted interventions that promote health by establishing healthy lifestyles and positive adaptive behaviours from a young age are required. In order to develop effective interventions that will be contextually relevant, baseline data for the UAE that measure the existing knowledge and attitudes of adolescents about healthy nutrition are required.

The aim of this study therefore was to assess the nutritional knowledge and habits of adolescents attending schools in the UAE.

\section{Methods}

\section{Study design}

This was a cross-sectional survey study. This design is appropriate when the research purpose is to collect initial or original data in a large population group, to describe trends and to measure the knowledge, attitudes or behaviours of a particular group $(32,33)$. G*Power software, V3.0.10 $0^{\circ}$ was used to calculate the required sample size. To achieve $95 \%$ power, with a medium effect size (0.4), and an alpha value of $0.05,300$ participants were needed.

\section{Sampling process}

Participants were drawn from 4 private schools in the Emirate of Sharjah in the UAE. A pragmatic decision was made to access the private school system because teaching is done in English and the students are thus competent in the language. The tools used were written in English and no current validated Arabic versions of the tools were available. Given that private schools are not segregated by gender, unlike the segregated public education system in the UAE, private schools offered easier access to both male and female students in the same location.

A 2-stage sampling process was undertaken. In the first stage, the names of all private schools in Sharjah $(n=80)$ were obtained from the relevant authorities, e.g. Sharjah Educational Zone. Each school was assigned a number and 4 numbers were randomly selected using True Random Number Generator software available online (https:// www.random.org/). In the second stage, the same computerized software was used to select classes from each of the 4 schools; only classes that contained the target age group (9-13 years) were included in the random selection process. Initially 4 classes from each school were selected with an average class size of 25 students. Information about the study was provided to the parents and they were asked to sign a consent form if they agreed for their child to participate. This initial process yielded 162 participants out of 400 who were invited, a response rate of $41 \%$. In order to achieve the required sample size, the class selection process was repeated enabling recruitment of a further 138 participants out of another 400 who were invited, a response rate 
of 34\% for this second round. Figure 1 illustrates the sampling process.

\section{Accessing participants}

On completion of the 2-stage sampling process, all students from the selected classes aged between 9 and 13 years who returned a valid signed consent form from their parents were included in this study. Students who did not return the consent form or could not complete the study questionnaire were excluded from the study. Eligible students who had returned the signed consent were then approached by the school nurses to take part in the study; they were provided with information about the purpose of the study, the nature of their participation, and how to complete the study survey. Students who agreed to participate were given a choice to complete the questionnaire immediately at school or later at home. In the second case, students were given an envelope and asked to return the questionnaire to the school nurse office. Students who chose to complete the survey at home were given one reminder to return their survey: 58 students chose to complete the form at home, and all required a reminder; following the reminder, 17 (29\%) students returned their completed questionnaires.

\section{Instrument}

The data collection tool was a selfadministered nutrition survey, adapted from a similar study conducted in Kuwait (one of the 6 GCC countries in the region) (34). The characteristics of Kuwaiti society in terms of culture, religion, politics and economics is very similar to that of the UAE as are the dietary habits and educational systems.

The questionnaire had 2 sections. The first section evaluated the students' knowledge about healthy nutrition, with 16 questions covering different dimensions of healthy nutrition. These are energy balance (Qs 1-4), knowledge taught using My Pyramid (a nutritional education tool developed in the
United States of America (USA) and widely used in the UAE: https://www. cnpp.usda.gov/mypyramid-graphics) (Qs 5-8), portion size (Qs 9-12) and healthy snacking (Qs 13-16). Each question had 4 options for the answer. The content validity of the questionnaire was considered appropriate after evaluation by a panel of experts in the fields of nutrition and elementary education. The second section evaluated dietary behaviours and included 5 questions that assessed consumption of fast foods, breakfast-skipping, caloric-dense food snacking, fruit intake and vegetable intake. This section was adapted from the Health Behavior Questionnaire and the School-Based Nutrition Monitoring student questionnaire, both with an acceptable internal consistency of greater than $0.6(35,36)$.

Thelevelofknowledgeabouthealthy nutrition was graded by the number of correct answers scored by the students on the relevant part of the questionnaire. The dietary behaviour part of the questionnaire included 5 Likert scale-type questions, where the student had to choose a correct answer from 4 options. Examples of the questions on both sections are shown below.

Sample question from the knowledge section.

The total number of servings of fruits and vegetables that you should eat every day is: at least 2 ; at least 5; at least 8; at least 10.

Sample question from the behaviour section.

Think about last week, did you eat snacks like candy, chocolate, chips, cookies, cake or ice-cream?: No, I did not eat any of the food listed or similar; Yes, I ate 1 of these foods 1 time last week; Yes, I ate 1 of these foods 2 times last week; Yes, I ate 1 of these foods 3 or more times last week.

\section{Ethical considerations}

Ethics approval for the study was obtained from theEthical ReviewCommittee for the Medical College and Health Sciences College for the University of

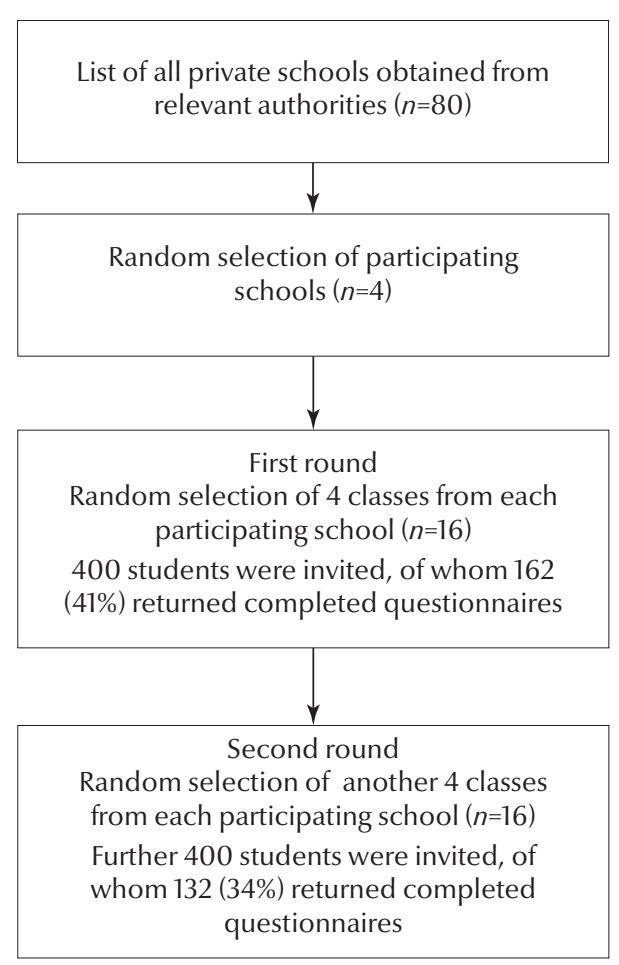

Figure 1 The study sampling process 
Sharjah and was communicated to the participating schools. As the proposed participants were minors, parental consent was required. An already established school protocol was used in which the school nurse liaised with the parents. Oral consent was sought from the students. Careful consideration was given to the potential for students to feel coerced into participating given the power imbalance between students, school nurses and researchers. In addition to the parental and student consent process, the adolescents were consulted regarding their preferences on when to complete the survey, which took 15 minutes on average to complete. Throughout the entire research process, regular checks were undertaken to ensure that the participants were happy to continue, and they were reminded that they could withdraw temporarily or permanently at any stage without any consequences. Parents were also advised that their child's participation was voluntary and informed of their right to withdraw their child from the study at any time.

Participant confidentiality and privacy were protected by ensuring that no personal information that would enable later identification was collected. Students were also reminded that they were not required to provide any identifying information while completing the survey. All study data were stored securely and were accessible only to the study researchers.

\section{Data analysis}

The surveys were graded manually. Data were coded, examined and prepared for analysis with SPSS, version 22. In the knowledge section, each correct response was allocated 1 point and each incorrect or no response was allocated 0 points. The 5 questions on dietary behaviours were assessed individually on a 4-point Likert scale: 4 indicated adoption of healthy nutritional behaviours on a daily basis, 3 indicated adoption of healthy nutritional behaviours frequently, 2 indicated adoption of healthy nutritional behaviours sometimes, and 1 indicated no adoption of healthy nutritional behaviours.

The maximum score for knowledge was 16 and the highest mean score for the behaviour was 4 . Higher scores indicated higher knowledge about nutrition and better dietary behaviour. Students' responses on the knowledge section were further categorized into level of knowledge about healthy nutrition: low knowledge level for scores less than 8/16; moderate knowledge for scores 8-12/16; and high knowledge for scores 13-16/16.

Basic data analysis described participants' demographics, level of knowledge and the relative healthiness of their behaviour. Associations between student's gender and knowledge levels, and between the level of knowledge and dietary behaviours were examined with the chi-squared test. $P<0.05$ was considered statistically significant.

\section{Results}

The age and sex of the study participants are shown in Table 1. The ages ranged from 9 to 13 years and $48 \%$ of the students were male.

Table 2 shows the nutritional knowledge and behaviour levels of the students. The great majority of the students (86\%) had low knowledge levels about nutrition and none had a high level of knowledge. Most of the students (61\%) had relatively healthy nutritional habits; only $34 \%$ had healthy habits.

Table 3 shows the percentage of correct and incorrect answers on each of the individual knowledge of nutrition questions according to sex. Each of the knowledge questions was answered incorrectly by more than half of the students, and $60 \%(9 / 16)$ of questions were answered wrongly by more than $65 \%$ of the students. The questions on which knowledge was particularly low were: the meaning of calorie, healthy snacks, identification of healthy foods, MyPyramid food guide, daily nutritional requirements and food content (e.g. fibre, fat).

Table 4 shows the reported eating behaviours of the students categorized by sex. In terms of dietary intake over the past week, $33 \%$ of the students had eaten none or 1 vegetable item only in the past week, $40 \%$ had eaten only 2 pieces of fruit or fewer, $25 \%$ had eaten unhealthy snacks 3 or more times, 19\% had eaten from fast food restaurants frequently or daily, and $36 \%$ had skipped breakfast frequently or daily.

There was a statistically significant relationship between gender and level of knowledge and reporting healthier eating habits $(P<0.001, P=0.002)$; girls had a greater level of knowledge and healthier eating habits. There was also a statistically significant relationship

\begin{tabular}{lc}
\hline Table 1 Characteristics of the study participants \\
\hline Characteristic & $\begin{array}{c}\text { No. }(\%) \\
(\boldsymbol{n}=300)\end{array}$ \\
\hline $\begin{array}{l}\text { Age (years) } \\
9\end{array}$ & $51(17)$ \\
10 & $59(20)$ \\
11 & $67(22)$ \\
12 & $66(22)$ \\
13 & $57(19)$ \\
Sex & \\
Male & $143(48)$ \\
Female & $157(52)$ \\
\hline
\end{tabular}




\begin{tabular}{|c|c|c|c|}
\hline \multirow{2}{*}{ Knowledge and behaviour } & Total $(n=300)$ & Males & Females \\
\hline & No. (\%) & No. (\%) & No. (\%) \\
\hline \multicolumn{4}{|l|}{ Knowledge level } \\
\hline Low & $257(86)$ & $134(52)$ & $123(48)$ \\
\hline Moderate & $43(14)$ & $9(21)$ & $34(79)$ \\
\hline High & $0(0 \%)$ & $0(0)$ & $0(0)$ \\
\hline \multicolumn{4}{|l|}{ Nutritional behaviour } \\
\hline Relatively unhealthy & $14(5)$ & $9(64)$ & $5(36)$ \\
\hline Relatively healthy & $183(61)$ & $99(54)$ & $84(46)$ \\
\hline Healthy & $103(34)$ & $35(34)$ & $68(66)$ \\
\hline
\end{tabular}

between nutritional knowledge and reported eating habits $(P<0.001)$; those students who had higher levels of knowledge about nutrition also reported healthier eating habits.

\section{Discussion}

This study explored students' knowledge of healthy nutrition and their eating habits. The issue of adolescent nutrition (1-5) and its effect on obesity has become a public health priority, both nationally within the UAE and globally (37). The increasing incidence of obesity and the resultant threat to the

Table 3 Percentage of correct and incorrect answers by the participants by sex

\begin{tabular}{|c|c|c|c|c|c|}
\hline & \multirow[t]{3}{*}{ Question } & \multicolumn{2}{|c|}{ Correct } & \multicolumn{2}{|c|}{ Incorrect } \\
\hline & & Males & Females & Males & Females \\
\hline & & No. (\%) & No. (\%) & No. (\%) & No. (\%) \\
\hline 1. & $\begin{array}{l}\text { Balancing energy in and energy out is important to maintain a } \\
\text { healthy body weight. Energy out is also known as: }\end{array}$ & $54(41)$ & 79 (59) & 89 (53) & $78(47)$ \\
\hline 2. & The goal for physical activity is to take steps every day & $37(41)$ & $54(59)$ & $106(51)$ & $103(49)$ \\
\hline 3. & $\begin{array}{l}\text { A unit of energy that comes from the food we eat and what we } \\
\text { drink is called: }\end{array}$ & $20(64)$ & $11(36)$ & $123(46)$ & $146(54)$ \\
\hline 4. & Calories in 1 cup of butter; calories in 1 cup of rice & $49(40)$ & $75(60)$ & $94(53)$ & $82(47)$ \\
\hline 5. & $\begin{array}{l}\text { A guide that helps us to balance what we eat with regular physical } \\
\text { activity is called: }\end{array}$ & $66(52)$ & $60(48)$ & $77(44)$ & $97(56)$ \\
\hline 6. & $\begin{array}{l}\text { A guide that helps us to evaluate what the nutritional contents of } \\
\text { food products are is called: }\end{array}$ & $31(56)$ & $24(44)$ & $112(46)$ & $133(54.3)$ \\
\hline 7. & My Pyramid recommends ... minutes of activity per day & $72(56)$ & $57(44)$ & $71(42)$ & $100(58)$ \\
\hline 8. & $\begin{array}{l}\text { According to My Pyramid, you should eat most from the food } \\
\text { group: }\end{array}$ & $29(37)$ & $50(63)$ & $114(52)$ & $107(48)$ \\
\hline 9. & A correct food serving refers to: & $69(48)$ & $74(52)$ & $74(47)$ & $83(53)$ \\
\hline 10. & $\begin{array}{l}\text { Total number of servings of fruits and vegetables you should eat } \\
\text { every day is: }\end{array}$ & $33(31)$ & $72(69)$ & $110(56)$ & $85(44)$ \\
\hline 11. & One cup of cooked rice is equal to: & $65(47)$ & $72(53)$ & $78(48)$ & $85(52)$ \\
\hline 12. & Every day you need ... cups of dairy & $39(56)$ & $30(44)$ & $104(45)$ & $127(55)$ \\
\hline 13. & The healthiest choice from the following is: & $16(27)$ & $43(73)$ & $127(53)$ & $114(47)$ \\
\hline 14. & Which food is considered a healthy snack? & $17(50)$ & $17(50)$ & $126(47)$ & $140(53)$ \\
\hline 15. & Which food had the most fibre? & $38(57)$ & $29(43)$ & $105(45)$ & $128(55)$ \\
\hline 16. & $\begin{array}{l}\text { Foods that contain high amounts of vitamins and minerals and } \\
\text { relatively few calories are called: }\end{array}$ & $65(48)$ & $69(52)$ & $78(47)$ & $88(53)$ \\
\hline
\end{tabular}




\begin{tabular}{|c|c|c|c|c|}
\hline \multicolumn{2}{|l|}{ Question } & \multirow{2}{*}{$\begin{array}{l}\text { Total }(n=300) \\
\quad \text { No. }(\%)\end{array}$} & \multirow{2}{*}{$\begin{array}{c}\text { Males } \\
\text { No. (\%) }\end{array}$} & \multirow{2}{*}{$\begin{array}{l}\text { Females } \\
\text { No. (\%) }\end{array}$} \\
\hline \multirow{5}{*}{$\begin{array}{l}\text { How frequently did you eat food from fast food } \\
\text { restaurants? }\end{array}$} & & & & \\
\hline & Daily & $19(6)$ & $10(53)$ & $9(47)$ \\
\hline & Frequently & $38(13)$ & $21(55)$ & $17(45)$ \\
\hline & Sometimes & $207(69)$ & $100(48)$ & $107(52)$ \\
\hline & Never & $36(12)$ & $12(33)$ & $24(67)$ \\
\hline \multirow[t]{4}{*}{ How frequently did you skip eating breakfast? } & Daily & $48(16)$ & $29(60)$ & $19(40)$ \\
\hline & Frequently & $59(20)$ & $31(53)$ & $28(48)$ \\
\hline & Sometimes & $76(25)$ & $31(41)$ & $45(59)$ \\
\hline & Never & $117(39)$ & $52(44)$ & $65(56)$ \\
\hline \multirow{4}{*}{$\begin{array}{l}\text { How frequently did you eat snacks like candy, chocolate, } \\
\text { chips, cookies, etc.? }\end{array}$} & $\geq 3$ times & $76(25)$ & $38(50)$ & $38(50)$ \\
\hline & 2 times & $51(17)$ & $27(53)$ & $24(47)$ \\
\hline & 1 time & $151(50)$ & $69(46)$ & $82(54)$ \\
\hline & Never & $22(7)$ & $9(41)$ & $13(59)$ \\
\hline \multirow[t]{4}{*}{ How many times did you eat fruits last week? } & None & $25(8)$ & $14(56)$ & $11(44)$ \\
\hline & 1 time & $36(12)$ & $19(53)$ & $17(47)$ \\
\hline & 2 times & $59(20)$ & $36(61)$ & $23(39)$ \\
\hline & 3 times & $180(60)$ & $74(41)$ & $106(59)$ \\
\hline \multirow[t]{4}{*}{ How many times did you eat vegetables last week? } & None & $36(12)$ & $18(50)$ & $18(50)$ \\
\hline & 1 time & $62(21)$ & $31(50)$ & $31(50)$ \\
\hline & 2 times & $94(31)$ & $52(55)$ & $42(45)$ \\
\hline & 3 times & $108(36)$ & $42(39)$ & $66(61)$ \\
\hline
\end{tabular}

population's future health highlight the urgent need to tackle the issue. Rapid and substantial societal changes have taken place in the UAE and other GCC countries over the past few decades, which have resulted in marked changes to the diet and lifestyle of much of the population. In response, the UAE government has outlined health promotion activities of importance and has specifically identified key objectives, including to implement school-based strategies to promote healthy nutritional habits among children and to increase activity levels to improve future health and reduce obesity $(31,38,39)$.

The results of our study are consistent with those of other reports that identified healthy nutrition knowledge gaps and negative nutritional habits among adolescents (1-5,7,8). A study in Morocco in 2016 identified moderate levels of overweight and obesity and undernourishment among Moroccan adolescents (1). Similarly a cross-sectional study in Mozambique in 2015 identified several serious micronutrient deficiencies among adolescent girls which could lead to serious health consequences, especially given that adolescent marriage and motherhood is a common practice (3). Likewise, a 2016 study reported on the nutritional profiles of adolescents of South Asian Indian descent in the USA (5). They found dietary patterns characterized by high levels of saturated fats with low potassium, magnesium, calcium, vitamin $\mathrm{D}$, and fibre intake. Such dietary habits are likely to predispose to future disease risk.

Positively influencing nutritional intake and promoting healthy behaviours is a challenge facing both developed and developing countries. However, the importance of addressing this issue early has been established with a focus on directing interventions towards children and adolescents within the school setting (23). Young people spend a lot of their time at school; they are learning rapidly and their behaviours are potentially more amenable to change than adults. It is thus suggested that school-based interventions that incorporate and promote healthy lifestyle behaviours are timely and potentially more effective during these formative years. Integrating current knowledge of nutrition into the overall curriculum and embedding healthy living practices within the educational system are important components to bring about the societal changes needed to protect the young people of the UAE from the health-related problems associated with obesity and related nutritional deficiencies.

Prior to planning and delivering interventions designed to promote healthy behaviours and improve nutritional knowledge, it is essential to identify the current nutritional knowledge and health habits of adolescents in the UAE context. The data obtained from 
this survey can inform future initiatives targeting specific areas requiring attention in young people aged 9-13 years.

Our results show a great lack of knowledge of healthy nutrition and healthy eating habits and suggest that, without active intervention, these young people are at risk of obesity, nutritional deficiencies and associated health problems. Consistent with previous research $(21,40)$ findings reporting a strong association between the nutritional knowledge of adolescents and their eating habits, our findings also showed a positive association between higher levels of nutritional knowledge and healthier eating habits, including eating more fruit and vegetables, eating breakfast more regularly, and eating fewer unhealthy snacks and less fast food.

Evidence about the benefits of multifaceted school-based health interventions on student knowledge of nutrition, health attitudes and behaviours has been described in international studies such as that conducted in 2014 in Alabama, USA (41). Similar interventions have also been reported targeting other populations. For example, a 2013 study in the USA also described a multifaceted educational intervention comprising experiential and interactive lessons, activities and demonstrations designed to improve the nutritional knowledge and behaviours among lowincome women from various ethnic backgrounds (42). Another study in 2013 study addressed the health literacy of parents as a key way of improving the weight of obese children by developing visual informational resources for them and a 2014 study in the USA used educational lessons for preschool children to increase their knowledge about healthy nutrition $(21,40)$.

\section{Limitations}

Although we surveyed a randomly selected sample of students from the 80 private schools in Sharjah, the results cannot necessarily be generalizable across the entire UAE. Variations in teaching curricula, differences between urban and more rural populations and differing levels of Westernization across the 7 UAE emirates may result in different findings to those found in this study. The response rate of $38 \%$ from the overall 800 students eligible for inclusion likewise limits the generalizability of the findings. Given that the students were asked about their dietary habits in the previous week, social desirability and recall bias might have affected their answers. Nevertheless, the large sample $(n=300)$ provides findings that could be considered indicative of the UAE adolescent population in the emirates where Westernization has progressed more rapidly. Future studies could consider employing more objective methods of measuring healthy behaviour and dietary intake with wireless-enabled technology devices and activity trackers.

\section{Conclusion}

The results of our study show low levels of knowledge about nutrition and less than healthy dietary behaviours and suggest that students in the UAE would benefit from population-specific educational interventions designed to build sound nutritional knowledge. In turn this can be used to motivate the dietary and health behavioural changes needed to promote health throughout the lifespan. However, the development and implementation of school-based interventions need to be informed by region-specific data (such as the data from this study), with careful attention given to culturally and contextually specific issues. In order to maximize the outcomes, consideration needs also to be given to the design of the intervention; parents, family and the local community should be included in the intervention if possible, and different techniques used to encourage healthy behaviours suitable to the age group of the targeted students.

Future studies to inform the development of effective interventions should determine the key sources of information about nutrition which currently influence the school-age population. Determining the preferred learning methods for this age group should also inform the development of future interventions.

It is also important to ensure that educational interventions are delivered across the entire continuum of education from preschool, through primary and secondary school and on into tertiary education to ensure continual reinforcement of healthy habits and to embed significant behavioural change across the lifespan.

Funding: None.

Competing interests: None declared.

\section{References}

1. Cherkaoui DI, Khalloufi N, Ghanname I, Khalfi H, Benkirane Y, Taboz H, et al. The prevalence of obesity and anemia among children schooled in public schools in the city of Rabat. J Dis Glob Heal. 2016;6(1):25-35

2. Nutrition in adolescence : issues and challenges for the health sector: issues in adolescent health and development. Geneva: World Health Organization; 2005:8-10 [WHO discussion paper on adolescence] (http://apps.who.int/iris/ bitstream/10665/43342/1/9241593660_eng.pdf, accessed 4 May 2017).

3. Korkalo L, Freese R, Alfthan G, Fidalgo L, Mutanen M. Poor micronutrient intake and status is a public health problem among adolescent Mozambican girls. Nutr Res. 2015;35(8):664-73.

4. Couroucli XI. Vitamin A deficiency in adolescents: rare or underdiagnosed? Lancet. 2016;387(10013):94.

5. Martyn-Nemeth P, Quinn L, Menon U, Shrestha S, Patel C, Shah G. Dietary Profiles of first-generation South Asian In- 
dian adolescents in the United States. J Immigr Minor Heal. 2017;19(2):309-17.

6. Centers for Disease Control and Prevention (CDC). Childhood obesity facts 2015 [website] (http://www.cdc.gov/healthyyouth/obesity/facts.htm, accessed 4 May 2017).

7. World Health Organization. Global Health Observatory data repository. Obesity (body mass index $>=30$ ), age-standardized (\%). Estimates by country. 2014 (http://apps.who.int/gho/ data/node.main.A900A?lang=en, accessed 4 May 2017).

8. World Health Organization. Global Health Observatory (GHO) data. Overweight and obesity by country (http://www.who. int/gho/ncd/risk_factors/overweight/en/, accessed 4 May 2017).

9. Andıran N, Çelik N, Akça H, Doğan G. Vitamin D deficiency in children and adolescents. J Clin Res Pediatr Endocrinol. 2012;4(1):25-9.

10. Mesías M, Seiquer I, Navarro MP. Iron nutrition in adolescence. Crit Rev Food Sci Nutr. 2013;53(11):1226-37.

11. Kawade R. Zinc status and its association with the health of adolescents: a review of studies in India. Glob Health Action. 2012;5:7353.

12. Fernandez Morales I, Aguilar Vilas MV, Mateos Vega CJ, Martinez Para MC. Breakfast quality and its relationship to the prevalence of overweight and obesity in adolescents in Guadalajara (Spain). Nutr Hosp. 2011;26(5):952-8.

13. Goldfield GS, Murray MA, Buchholz A, Henderson K, Obeid N, Kukaswadia A, et al. Family meals and body mass index among adolescents: effects of gender. Appl Physiol Nutr Metab. 2011 Aug;36(4):539-46.

14. Coppinger T, Jeanes YM, Hardwick J, Reeves S. Body mass, frequency of eating and breakfast consumption in 9-13-year-olds. J Hum Nutr Diet. 2012 Feb;25(1):43-9.

15. Traill WB, Chambers SA, Butler L. Attitudinal and demographic determinants of diet quality and implications for policy targeting. J Hum Nutr Diet. 2012 Feb;25(1):87-94.

16. Nurul-Fadhilah A, Teo PS, Huybrechts I, Foo LH. Infrequent breakfast consumption is associated with higher body adiposity and abdominal obesity in Malaysian school-aged adolescents. PLoS One. 2013;8(3):e59297.

17. Burgess-Champoux TL, Larson N, Neumark-Sztainer D, Hannan PJ, Story M. Are family meal patterns associated with overall diet quality during the transition from early to middle adolescence? J Nutr Educ Behav. 2009;41(2):79-86.

18. Stewart SD, Menning CL. Family structure, nonresident father involvement, and adolescent eating patterns. J Adolesc Health. 2009 Aug;45(2):193-201.

19. Quirk-Baillot D, Flament MF, Allen A, Obeid N, Remy B, Falissard B, et al. The Attitudes and Patterns of Eating (APE) Questionnaire: development and factor analysis in a U.S. adolescent community sample. Eat Weight Disord. 2012 Jun;17(2):e147-56.

20. Melbye EL, Ogaard T, Overby NC, Hansen H. Parental foodrelated behaviors and family meal frequencies: associations in Norwegian dyads of parents and preadolescent children. BMC Public Health. 2013;13:820.

21. White RO, Thompson JR, Rothman RL, McDougald Scott AM, Heerman WJ, Sommer EC, et al. A health literate approach to the prevention of childhood overweight and obesity. Patient Educ Couns. 2013 Dec;93(3):612-8.

22. Manios Y, Moschonis G, Chrousos GP, Lionis C, Mougios V, Kantilafti $M$, et al. The double burden of obesity and iron deficiency on children and adolescents in Greece: the Healthy Growth Study. J Hum Nutr Diet. 2013 Oct;26(5):470-8.

23. Jones RA, Lubans DR, Morgan PJ, Okely AD, Parletta N, Wolfenden L, et al. School-based obesity prevention interventions: practicalities and considerations. Obes Res Clin Pract. 2014;8(5):e497-510
24. Quinn M. Introduction of active video gaming into the middle school curriculum as a school-based childhood obesity intervention. J Pediatr Health Care. 2013 Jan;27(1):3-12.

25. Pbert L, Druker S, Gapinski MA, Gellar L, Magner R, Reed G, et al. A school nurse-delivered intervention for overweight and obese adolescents. J Sch Health. 2013 Mar;83(3):182-93.

26. Vericker TC. Children's school-related food and physical activity behaviors are associated with body mass index. J Acad Nutr Diet. 2014 Feb;114(2):250-6.

27. Centers for Disease Control and Prevention. School health guidelines to promote healthy eating and physical activity. MMWR Recomm Rep. 2011 Sep 16;60(RR-5):1-76.

28. Moreno LA, De Henauw S, Gonzalez-Gross M, Kersting M Molnar D, Gottrand F, et al. Design and implementation of the Healthy Lifestyle in Europe by Nutrition in Adolescence CrossSectional Study. Int J Obes. 2008 Nov;32 Suppl 5:S4-11

29. Schumacher K, Meleis A. Transitions: A central concept in nursing. In: Melies A, editor. Transitions theory: Middle-range and situational-specific theories in nursing research and practice. New York: Spring Publishing; 2010.

30. Ng SW, Zaghloul S, Ali H, Harrison G, Yeatts K, El Sadig M, et al. Nutrition transition in the United Arab Emirates. Eur J Clin Nutr. 2011 Dec;65(12):1328-37.

31. Al-Khouri A. Population growth and government modernisation efforts the case of GCC countries. Int Journal Res Manag Technol. 2010 (http://www.id.gov.ae/assets/4LuayQ86g1t. pdf.aspx, accessed 4 May 2017)

32. Creswell JW. Research design: Qualitative, quantitative, and mixed methods approaches. Los Angeles (CA): Sage; 2013.

33. Maltby J, Williams GA, McGarry J, Day L. Research methods for nursing and healthcare. Oxford: Routledge; 2014.

34. Kalendar SA. Development and evaluation of let's eat smart: a pilot school based nutrition intervention for elementary school children in Kuwait [Thesis]. Oxford: University of Mississippi; 2011.

35. Edmundson E, Parcel GS, Feldman HA, Elder J, Perry CL, Johnson CC, et al. The effects of the Child and Adolescent Trial for Cardiovascular Health upon psychosocial determinants of diet and physical activity behavior. Prev Med. 1996;25(4):442-54.

36. Hoelscher DM, Day RS, Kelder SH, Ward JL. Reproducibility and validity of the secondary level school-based nutrition monitoring student questionnaire. J Am Diet Assoc. 2003 Feb;103(2):186-94

37. Griffiths N, Houghton K. The development and implementation of a hospital based paediatric orthopaedic nursing transition program. J Pediatr Nurs. 2013;28(6):e50-6. 10.1016/j. pedn.2012.12.009

38. Guide of health and nutritional practice of school canteens. Dubai: Dubai Health Authority; 2015 (https://login. dm.gov.ae/wps/wcm/connect/0f9efc3b-ac2d-4169-a426$170 \mathrm{e} 55 \mathrm{a} 02 \mathrm{c06} /$ School+canteens.pdf?MOD=AJPERES, accessed 4 May 2017). 39.

39. ADEC public schools (P-12). Policy manual. Abu Dhabi: Abu Dhabi Educational Council (ADEC); 2014 (https://www.adec. ac.ae/en/MediaCenter/Publications/p-12 Policy manual 2014-15 - ENG/HTML/index.html, accessed 4 May 2017).

40. Sigman-Grant M, Byington TA, Lindsay AR, Lu M, Mobley $A R$, Fitzgerald N, et al. Preschoolers can distinguish between healthy and unhealthy foods: the all 4 kids study. J Nutr Educ Behav. 2014;46(2):121-7.

41. Morgan ZA, Ulrich P, Simmons KP, Gropper SS, Connell LJ, Daniels MK, et al. Effectiveness of a multi-faceted, schoolbased health intervention program with 4 th graders in Alabama. Child Youth Serv Rev. 2014;37:46-54.

42. Rustad C, Smith C. Nutrition knowledge and associated behavior changes in a holistic, short-term nutrition education intervention with low-income women. J Nutr Educ Behav. 2013;45(6):490-8. 